\title{
Síndrome de text-neck: una nueva pandemia en la era smartphone
}

Text-neck syndrome: a new pandemic in the smartphone era

\section{Sr. Editor:}

La humanidad en la actual era digital ha incorporado y aceptado universalmente al smartphone como parte esencial de nuestra vida diaria, el uso masivo se ha centrado especialmente en la población adulta joven; a quienes es frecuente observarlos dándole uso absorto mientras desarrollan sus actividades cotidianas.

Esto ha permitido acortar las brechas geográficas, facilitando la comunicación, propagación del conocimiento y acceso ainformación; sin embargo, se ha descrito que el uso excesivo de los Smartphone impacta negativamente en las relaciones interpersonales socioafectivas (Phubbing) y deterioran la salud, debido a la postura corporal adoptada al utilizar excesivamente el smartphone; originando, una emergente afección del sistema musculo-esquelético conocido como: Síndrome de Text-Neck (1).

Los primeros estudios datan del año 2008 gracias a las investigaciones realizadas por Fishman (2), quiropráctico estadounidense quien añadió el término "Text-Neck" para describir una lesión por estrés repetitivo y dolor sostenido debido a la posición reclinada del cuello durante el uso excesivo de teléfonos inteligentes o smarthphone, tablets y laptops. Fishman fundó el Instituto Text-Neck durante el año 2009, donde continuó con su labor investigadora en el tema logrando diseñar un algoritmo terapéutico que contribuyó al diagnóstico y manejo de esta afección $(1,2)$.
Desde el punto de vista biofísico, este síndrome, conocido también como "Turtle Neck Posture" es consecuencia de la pérdida de la curva natural de la columna cervical, secundaria a la postura inclinada hacia delante que adopta la cabeza con respecto a los hombros de manera crónica (2). Esta nueva posición incrementa el peso que soportan las articulaciones cervicales. Fisiológicamente, la columna cervical soporta el peso de la cabeza, esto incrementa en relación directa a los grados de flexión de la cabeza, desde $5 \mathrm{~kg}$ en la posición anatómica, con $0^{\circ}$ de inclinación, $18 \mathrm{~kg}$ cuando está inclinada 30 grados y $27 \mathrm{~kg}$ cuando está a $60^{\circ}(3,4)$.

En la actualidad el Síndrome de Text-Neck tiene una prevalencia de $86,9 \%$ en población infantil y adolescente, en su mayoría mujeres (4); asimismo, se ha descrito que el $35 \%$ de la población escuchó en algún momento de su vida sobre esta patología mientras que solo el $8 \%$ de ellos tiene conocimiento sobre esta (5).

El Síndrome de Text-Neck se manifiesta como, dolor cervical asociado a tensión $(71,2 \%)$, cefalea $(63,3 \%)$, irritabilidad $(54,5 \%)$ y ansiedad $(50,7 \%)$ $(5,6)$. Además, manifestaciones oculares como astenopia, xeroftalmia y miopía (21\%); efectos psicológicos como irritabilidad, estrés, ansiedad y depresión (82\%) (4). La cronicidad de esta patología conlleva a desgarros musculares y degeneración osteomuscular a nivel cervical, la cual en sus formas severas puede requerir de cirugías como discectomía anterior y artroplastia (3).

Sociedad Científica Medico Estudiantil San Cristóbal. Escuela Profesional de Medicina Humana. Universidad Nacional de San Cristóbal de Huamanga. Ayacucho, Perú.

2 Área de Medicina. Centro de Salud de Ambo. Huánuco, Perú.

a Estudiante de Medicina;

b Médico Cirujano. 
En la actual era tecnológica es imposible evitar el uso de los smarthphone a pesar de los efectos adversos hacia la salud; por lo tanto, urge la necesidad de mayores investigaciones con la finalidad de implementar lineamientos de prevención y promoción de la salud en toda la población usuaria de estas tecnologías que están en riesgo del temido Síndrome de Text-Neck.

\section{Dercy Centeno-Leguía ${ }^{1,}$, W Samir Cubas ${ }^{2, b}$}

\section{Correspondencia:}

Dercy Centeno Leguia

Avenida Maravillas $\mathrm{N}^{\circ} 296$, Ayacucho, Huamanga, Ayacucho, Perú.

Teléfono: 988202752

Correo electrónico: dercycenteno@gmail.com

\section{REFERENCIAS BIBLIOGRÁFICAS}

1. Neupane S, Ali UI, Mathew A. Text Neck SyndromeSystematic Review. IJIR. 2017;3(7):141-148.

2. Fishman D. Text Neck: A Global Epidemic [Sede web] Text Neck Institute. Louisville, Colorado. 2015. Disponible en: http://www.text-neck.com/

3. Hansraj KK. Assessment of stresses in the cervical spine caused by posture and position of the head. Surg Technol Int. 2014; 25(25):277-9.

4. Fares J, Fares MY, Fares Y. Musculoskeletal neck pain in children and adolescents: Risk factors and complications. Surg Neurol Int. 2017; 8:72. DOI:10.4103/sni.sni_445_16

5. Samani PP, Athavale NA, Shyam A, Sancheti PK. Awareness of text neck syndrome in young-adult population. Int J Community Med Public Health. 2018; 5(8): 3335-3339. DOI: http://dx.doi.org/10.18203/ 2394-6040.ijcmph20183057

Recibido: 01/04/2019 